\title{
CRENÇA DE AUTOEFICÁCIA ACADÊMICA NO DESENVOLVIMENTO DO LETRAMENTO ESTATÍSTICO
}

\author{
Paulo Cesar Oliveira ${ }^{1}$ \\ Nelson Antonio Pirola ${ }^{2}$
}

\section{RESUMO}

Este artigo tem por objetivo apresentar os resultados de uma pesquisa envolvendo possíveis relações existentes entre as crenças de autoeficácia, sob o enfoque de Albert Bandura, e o desempenho de alunos dos anos finais do Ensino Fundamental e do Ensino Médio, na resolução de tarefas relacionadas ao letramento estatístico, na perspectiva de Iddo Gal. Participaram deste estudo 163 alunos do $9^{\circ}$ ano do Ensino Fundamental e 165 da $3^{a}$ série do Ensino Médio que responderam a uma escala de autoeficácia associada a resolução de um conjunto de sete itens com tarefas estatísticas. Os resultados dessa pesquisa revelou o teor das crenças de autoeficácia positivas e negativas influenciaram no êxito e fracasso dos alunos na resolução das tarefas. A análise dos protocolos escritos apontaram lacunas no conhecimento estatístico, matemático e habilidades de letramento, interferindo assim no desenvolvimento do letramento estatístico.

Palavras-chave: Escala Likert. Alfabetização. Estatística.

\section{BELIEF IN ACADEMIC SELF-EFFICACY IN THE DEVELOPMENT OF STATISTICAL LITERACY}

\begin{abstract}
This article aims to present the results of a research involving possible existing relationships between the beliefs of self-efficacy, under the focus of Albert Bandura, and the performance of students in the final years of elementary and high school, in solving tasks related to the statistical literacy, from the perspective of Iddo Gal. 163 students from the 9th grade of elementary school and 165 from the 3rd grade of high school participated in this study, who answered a self-efficacy scale associated with solving a set of seven items with statistical tasks. The results of this research revealed that the content of positive and negative self-efficacy beliefs influenced students' success and failure in solving tasks. The analysis of the written protocols pointed out gaps in statistical knowledge, mathematics and literacy skills, thus interfering in the development of statistical literacy.

Keywords: Likert scale. Literacy. Statistic.

1 Doutorado em Educação Matemática. Bolsista no Programa Nacional de Pós Doutorado/CAPES na Faculdade de Ciências da UNESP, Bauru. Professor Associado da Universidade Federal de São Carlos, Sorocaba, São Paulo, Brasil. Orcid iD: https://orcid.org/0000-0003-2514-904X. E-mail: paulodfqm@gmail.com

2 Livre-Docente em Educação Matemática. Universidade Estadual Paulista "Júlio de Mesquita Filho" - UNESP, Bauru, São Paulo, Brasil. Orcid iD: https://orcid.org/0000-0002-82151317. E-mail: nelson.pirola@unesp.br
\end{abstract}

Revista Exitus, Santarém/PA, Vol. 11, p. 01 - 25, e020166, 2021. 


\section{CREENCIA EN LA AUTOEFICACIA ACADÉMICA EN EL DESARROLLO DE LA ALFABETIZACIÓN ESTADÍSTICA}

\section{RESUMEN}

Este artículo tiene como objetivo presentar los resultados de una investigación que involucra las posibles relaciones existentes entre las creencias de autoeficacia, bajo el enfoque de Albert Bandura, y el desempeño de los estudiantes de los últimos años de Primaria y Secundaria, en la resolución de tareas relacionadas con la estadística. alfabetización, desde la perspectiva de Iddo Gal. En este estudio participaron 163 alumnos de $9^{\circ}$ de Primaria y 165 de $3^{\circ}$ de Secundaria, quienes respondieron una escala de autoeficacia asociada a la resolución de un conjunto de siete ítems con tareas estadísticas. Los resultados de esta investigación revelaron que el contenido de las creencias de autoeficacia positivas y negativas influyó en el éxito y el fracaso de los estudiantes en la resolución de tareas. El análisis de los protocolos escritos señaló lagunas en el conocimiento estadístico, matemáticas y alfabetización, interfiriendo así en el desarrollo de la alfabetización estadística.

Palabras clave: Escala Likert. Literatura. Estadística.

\section{INTRODUÇÃO}

O artigo em questão envolve a análise de um teste de desempenho escolar contendo 7 itens com proposições estatísticas distribuídos em 4 tarefas para que estudantes possam expressar e justificar sua crença de autoeficácia, atribuindo pontos de 1 a 6 em uma escala do tipo Likert. Na sequência, os alunos são convidados a resolver esses itens do teste, dispostos por um conjunto de 4 tarefas estatísticas.

Essa pesquisa visa responder duas questões de investigação: existe relação entre as crenças de autoeficácia e o desempenho na resolução de tarefas estatísticas? Que lacunas os alunos apresentam no decorrer das suas atividades estatísticas que comprometem o desenvolvimento do letramento estatístico?

O conteúdo das 4 tarefas estatísticas foram formuladas levando em conta, por um lado, o conteúdo do modelo de letramento estatístico proposto por Gal $(2002,2019)$. Por outro lado, resultados de pesquisas obtidos no Grupo de Estudos e Planejamento de Aulas de Matemática - GEPLAM, como é o caso de Cobello e Oliveira (2019). Estes autores, ao analisarem o Currículo do Estado de São Paulo (SÃO PAULO, 2012) e seus materiais de apoio constataram que os conteúdos de Estatística contidos nos blocos temáticos Números e Relações contemplaram excessivamente cálculos e 
construção de gráficos e tabelas, principalmente na abordagem de medidas de tendência central (média, mediana e moda) e de medidas de dispersão (desvio médio e desvio padrão), revelando lacunas na produção de dados a serem submetidos à interpretação estatística das informações dispostas.

Neste sentido, concebemos que o estudante inserido em tarefas envolvendo a investigação estatística em temas sociais, por exemplo, como a violência urbana, pode contribuir na sua crença de autoeficácia quanto à sua capacidade em resolver questões propostas sobre o assunto. Temos considerado que o letramento estatístico demanda um diagnóstico por parte do professor sobre os conhecimentos prévios dos alunos, especificamente, noções básicas de estatística e probabilidade. Na perspectiva de Gal (2002), essas noções não podem ser discutidas em termos absolutos, pois dependem do nível de letramento estatístico esperado pelos cidadãos. Essas noções são fundamentais para entender como e por que determinada coleta de dados foi realizada, além da familiaridade com formas distintas de representações das informações estatísticas, suas interpretações e comunicação das inferências estatísticas (OLIVEIRA; MACEDO, 2018).

A redação deste artigo envolveu seções primárias contendo a apresentação da fundamentação teórica da pesquisa (letramento estatístico e crença de autoeficácia) e do percurso metodológico envolvendo a natureza da pesquisa, os instrumentos de produção e análise das informações, bem como os sujeitos participantes da pesquisa.

\section{ASPECTOS DOS APORTES TEÓRICOS DA PESQUISA}

Os estudos de Iddo Gal no doutorado em psicologia cognitiva na Universidade da Pensilvânia levaram-no a pesquisar sobre a tomada de decisões e o raciocínio probabilístico, e mais tarde a se perguntar como o raciocínio estatístico e as habilidades probabilísticas podem ser melhoradas de maneira mais geral.

O autor apresenta uma concepção ampla de letramento estatístico, 
abrangendo diferentes componentes:

a) Capacidade das pessoas de interpretar e avaliar criticamente uma informação estatística, os argumentos relacionados aos dados ou aos fenômenos aleatórios, que podem ser encontrados em diversos contextos; b) Capacidade das pessoas de discutirem ou comunicarem suas reações a essas informações estatísticas, tais como a sua compreensão do significado da informação, suas opiniões sobre as implicações desta informação ou suas preocupações sobre a aceitabilidade de determinadas conclusões (GAL, 2002, p.2).

Gal (2002) teve como foco a preocupação em verificar como as pessoas podem se tornar eficazes leitores frente a informações com dados estatísticos. Para isto, propôs um modelo no qual implica que o letramento estatístico necessita a ativação conjunta de cinco bases de conhecimentos inter-relacionadas: habilidades de letramento, conhecimento estatístico, conhecimento matemático, conhecimento do contexto e apresentar postura crítica. Interligada às bases de conhecimento, Gal (2002) contemplou também dois elementos de disposição: a postura crítica em conjunto com crenças e atitudes.

Gal $(2002,2019)$ abordou que o tema letramento estatístico deve ser muito discutido no meio acadêmico e educacional, pois a nossa sociedade possui cada vez mais acesso a informações de diferentes maneiras, porém, como que estas informações estão sendo interpretadas, entendidas e qual o propósito de sua produção? Tal questionamento é relevante, pois as pessoas apropriam-se de informações estatísticas e, na maioria das vezes, não são produtoras das mesmas e sequer conhecem o processo de produção e veiculação de informações dessa natureza.

A postura crítica envolve a predisposição do estudante em questionar - conteúdo das informações obtidas que podem apresentar dados tendenciosos ou incompletos de forma intencional ou não. As atitudes são sentimentos estáveis e intensos que se desenvolvem por meio da compreensão gradual de respostas emocionais, positivas ou negativas (gosto/não gosto, agradável/desagradável). Na literatura brasileira em Psicologia da Educação Matemática é notório utilizar a definição de Brito 
(1996, p.11) sobre o que é atitude, a qual associa a disposição pessoal do sujeito agir em determinadas situações, ou seja, "[...] dirigida a objetos, eventos ou pessoas, que assume diferente direção e intensidade de acordo com as experiências do indivíduo. Além disso, apresenta componentes do domínio afetivo, cognitivo e motor".

A crença relaciona-se à capacidade do indivíduo quanto ao raciocínio estatístico, o qual depende do desenvolvimento de uma visão positiva de si mesmo, assim como o desejo sobre o 'pensar estatisticamente' em determinadas situações. Concordamos com Martins e Ponte (2010, p.9) que o letramento, o raciocínio e o pensamento estatístico são três conceitos inter-relacionados, porque o letramento ou "literacia estatística apoia-se no pensamento estatístico e este, por sua vez, tem como núcleo fundamental o raciocínio estatístico". Para estes autores, o raciocínio estatístico contempla os modos de raciocinar e resolver problemas próprios da Estatística, enfatizando técnicas, representações e processos de inferência.

O pensamento estatístico envolve a necessidade de atender à natureza e a variabilidade dos dados estatísticos, valorizando de modo determinante o papel do contexto, como essencial não só para observar, mas também interpretar as mensagens existentes nos dados, e inferindo julgamentos sobre situações reais. Finalmente, as considerações sobre as finalidades do ensino da Estatística na sociedade atual trouxeram para um primeiro plano as preocupações com a literacia ou letramento estatístico.

No aporte teórico-metodológico de Gal (2002, 2019) sentimos a necessidade de mensurar a crença do sujeito, ou seja, o quanto o indivíduo acredita ser capaz de interpretar informações estatísticas. Recorremos à Teoria Social Cognitiva (TSC) de Bandura (2008), na qual considera-se o comportamento humano como uma expressão de uma relação denominada reciprocidade triádica, sobre a qual, o comportamento do indivíduo, os fatores pessoais e o ambiente, influenciam-se mutuamente.

Nesse contexto, a escola é um ambiente potencial em relações entre seus membros e, como consequência, mudanças comportamentais são esperadas nos alunos. Pajares e Olaz (2008, p.97) apoiam-se na TSC para 
orientar-nos de que "os professores podem trabalhar para melhorar os estados emocionais de seus alunos e para corrigir suas auto-crenças e hábitos negativos (fatores pessoais), melhorar suas habilidades acadêmicas e práticas auto-regulatórias (comportamento) [...]".

A noção de autoeficácia também é um constructo fundamental na TSC, definida por Bandura (1994) como as crenças que o indivíduo tem sobre sua capacidade de realizar com sucesso determinada atividade. Quanto maior for o senso de autoeficácia, maiores serão os esforços do indivíduo. Segundo Bandura (1994, p.71), "pessoas com altas crenças em suas capacidades aproximam-se de tarefas difíceis como desafios a serem superados e não como ameaças a serem evitadas [...]". Em contrapartida, pessoas que duvidam de suas capacidades evitam tarefas que consideram difíceis, pois as veem como ameaçadoras. Bandura (1994, p.71) complementa que sujeitos com baixa autoeficácia têm "baixas aspirações e fraco compromisso com as metas que escolheram para prosseguir".

Através do exposto até aqui, percebe-se que, especialmente em relação às crenças de autoeficácia acadêmica, interferem na motivação e no esforço dos estudantes diante das tarefas propostas. Desta forma, no âmbito educacional, estudantes com baixo senso de autoeficácia em conteúdos escolares podem sofrer situações de fracasso escolar, por conta do mau desempenho nas tarefas propostas.

Na Matemática para a Educação Básica não encontramos trabalhos envolvendo crenças de autoeficácia na relação com 0 ensinoaprendizagem de tópicos da Estatística (OLIVEIRA, PIROLA, MARQUES JUNIOR, 2020). No campo da resolução de problemas em matemática, uma revisão na base SCIELO - Scientic Eletronic Library Online; Sander, Pirola e Brocardo (2020, p.80) encontraram "somente três trabalhos que articulam crenças de autoeficácia com a Matemática". A contribuição brasileira ainda é modesta no campo educacional, inclusive na área da Matemática escolar.

Passamos aos aspectos metodológicos da pesquisa foco deste artigo; mais especificamente, sua natureza e o processo de produção e análise das 
informações, as quais foram obtidas com a participação de 328 estudantes de três escolas públicas estaduais do município de Pilar do Sul, no estado de São Paulo.

\section{PERCURSO METODOLÓGICO DA PESQUISA}

Uma pesquisa quali-quantitativa, de acordo com Creswell (2010, p.35), utiliza uma metodologia mista, a qual "emprega estratégias de investigação que envolvem coleta de dados simultânea ou sequencial para melhor entender os problemas de pesquisa". Com base nos aportes teóricos do letramento estatístico e a crença de autoeficácia acadêmica, foi elaborado o teste de desempenho escolar, o qual propiciou obtermos as informações submetidas à análise. As informações obtidas com 163 alunos do $9^{\circ}$ ano do Ensino Fundamental e 165 da $3^{a}$ série do Ensino Médio de forma mútua, pela aplicabilidade da escala de autoeficácia e a resolução das tarefas estatísticas, tiveram o mesmo grau de importância, e sua integração ocorreu na fase de análise do material empírico.

Oliveira, Pirola e Marques Junior (2020) publicaram o estudo das propriedades psicométricas utilizadas na validação dessa escala de autoeficácia para estudantes concluintes do Ensino Fundamental e Médio em relação à resolução de tarefas ao letramento estatístico. Para a continuidade desse texto, construímos duas seções primárias: a primeira envolvendo aspectos da escala de crença de autoeficácia em tarefas estatísticas do tipo Likert (instrumento que teve análise quantitativa) e a segunda contemplando a análise qualitativa das produções escritas dos alunos em relação ao desenvolvimento do letramento estatístico.

\section{ESCALA DE AUTOEFICÁCIA ACADÊMICA}

A escala de crença de autoeficácia em tarefas estatísticas do tipo Likert, contou com 7 itens para análise de desempenho escolar. Em cada item foram atribuídas as seguintes pontuações: discordo totalmente (1 ponto), discordo (2 pontos), maior parte discordo (3 pontos), maior parte concordo (4 pontos), concordo (5 pontos) e concordo totalmente 16 pontos). Os pontos 1, 2 e 3 indicam crença de autoeficácia negativa, 
enquanto as demais pontuações expressam crenças de autoeficácia positiva.

O aluno ao ler cada proposição atribuiu uma pontuação na escala de 1 a 6, a qual expressa sua crença em ser capaz ou não de resolver cada uma das 7 itens propostos no teste de desempenho escolar. Atrelado a isso, solicitamos que para cada proposição apresentada, o aluno fizesse o registro escrito justificando a pontuação escolhida. Como exemplo, destacamos o enunciado da terceira tarefa e uma das proposições: Considere a lista de filmes disponíveis nos cinemas da região metropolitana de Sorocaba na segunda quinzena de julho de 2019: "O Rei Leão", "HomemAranha: longe de casa", "Toy Story 4", "Turma da Mônica: laços", "Annabelle 3: de volta para casa" e "Pets: a vida secreta dos bichos 2". Eu me sinto motivado em ajudar a levantar informações sobre minha turma e elaborar um gráfico que relacione cada filme e o número de vezes (frequência) que foi assistido. Pontuação___ Por que?

Para verificar a existência ou não da relação entre as crenças de autoeficácia e o desempenho na resolução de tarefas estatísticas, iniciamos a busca por respostas aplicando o teste de Wilcoxon-Mann-Whitney ou simplesmente teste de Mann-Whitney, pelo fato de possuirmos duas amostras independentes com variáveis ordinais, no caso, itens de uma escala Likert com variabilidade qualitativa de 'discordo totalmente' até 'concordo totalmente'. Em termos de procedimentos, de acordo com as recomendações de Vieira (2011), formulamos a hipótese nula $\left(H_{0}\right)$, calculamos o valor da estatística do teste (valor-p) ao nível de significância de $5 \%$ e, com base na grandeza dessa estatística, avaliamos a rejeição ou não de $\mathrm{H}_{0}$

A hipótese nula é que o grupo de 328 alunos, sendo 163 do $9^{\circ}$ ano do Ensino Fundamental (EF) e 165 estudantes da $3^{a}$ série do Ensino Médio (EM) não diferem em localização, isto é, os dados (escores totais) estão dispersos em torno de um mesmo ponto nas duas amostras. Caso a hipótese nula seja rejeitada pelo teste, então é possível afirmar que os dados trazem evidências suficientes de que as duas amostras não têm a mesma distribuição, tomando 
por base a média.

O valor-p é definido como a probabilidade de se observar um valor da estatística de teste maior ou igual ao encontrado (valor-p =0,000002147). Dado que o valor de corte é de 0,05 e maior que o valor-p calculado, rejeitamos a hipótese nula e concluímos que os dados de cada amostra estão dispersos em torno das respectivas médias, conforme os valores apresentados nas Tabelas 1 e 2:

TABELA 1 - Medidas descritivas dos escores totais de 163 estudantes do $9^{\circ}$ ano (EF) de Pilar do Sul-SP, no ano de 2020

\begin{tabular}{c|c|c|c|c|c|}
\hline Amostra & Mínimo & Mediana & Média & Máximo & Desvio-padrão \\
\hline 163 & 7 & 28 & 28,13 & 42 & 7,102 \\
\hline
\end{tabular}

Fonte: os autores

TABELA 2 - Medidas descritivas dos escores totais de 165 estudantes da $3^{a}$ série (EM) de Pilar do Sul-SP, no ano de 2020

\begin{tabular}{|c|c|c|c|c|c|}
\hline Amostra & Mínimo & Mediana & Média & Máximo & Desvio-padrão \\
\hline 165 & 7 & 32 & 31,58 & 42 & 6,515 \\
\hline
\end{tabular}

Fonte: os autores

A distribuição dos escores (pontos da escala Likert) da amostra dos alunos da $3^{a}$ série do Ensino Médio (EM) foi superior aos dados da amostra do $9^{\circ}$ ano do Ensino Fundamental (EF), tomando por base o valor mediano 3,5 na escala, com variabilidade de 1 a 6 pontos. Como o instrumento contém sete itens de coleta de dados, a pontuação mediana é dada por 3,5*7= 24,5 pontos.

A Tabela 3 mostra uma diferença significativa das pontuações totais entre alunos do $9^{\circ}$ ano (EF) e da $3^{a}$ série (EM). Indivíduos com total de pontos superior a 24,5 (mediana) foram classificados como 'crença de autoeficácia positiva' e o restante 'crença de autoeficácia negativa'.

TABELA 3 - Classificação dos escores totais de 328 estudantes de $9^{\circ}$ ano (EF) e $3^{a}$ série (EM) de Pilar do Sul-SP, no ano de 2020

\begin{tabular}{cccc}
\hline & $\begin{array}{c}\text { Crença de } \\
\text { autoeficácia } \\
\text { negativa }\end{array}$ & $\begin{array}{c}\text { Crença de } \\
\text { autoeficácia } \\
\text { positiva }\end{array}$ & Total \\
\hline $9^{\circ}$ ano (EF) & $50(30,7 \%)$ & $113(69,3 \%)$ & $163(49,7 \%)$ \\
\hline $3^{a}$ série (EM) & $19(11,5 \%)$ & $146(88,5 \%)$ & $165(50,3 \%)$ \\
\hline Total & $69(21,04 \%)$ & $259(78,96 \%)$ & $328(100 \%)$ \\
\hline
\end{tabular}

Fonte: os autores 
Analisando o conteúdo da Tabela 1, verificamos que aproximadamente $30,7 \%$ dos alunos do $9^{\circ}$ ano estão abaixo do valor central enquanto que apenas aproximadamente $11,5 \%$ da $3^{a}$ série (EM) estão abaixo da mediana de 24,5 pontos.

Pajares e Olaz (2008) abordaram a força de uma crença usando os atributos 'negativo/positivo' e 'fraco/forte'. Nesta seção avaliamos a força da crença com relação ao desempenho dos estudantes.

$\mathrm{Na}$ formulação dos 7 itens do teste de desempenho escolar, designamos dois agrupamentos de conhecimentos: os 5 primeiros itens das tarefas contemplaram a coleta, organização, representação e interpretação de dados, por meio da construção de tabelas e gráficos. Os 2 últimos itens envolveram o cálculo da mediana, razão ou proporção, além da interpretação dos seus resultados.

O nível de concordância que englobou os atributos 'maior parte concordo', 'concordo' e 'concordo totalmente', para os 5 primeiros itens das tarefas do $9^{\circ}$ ano (EF) oscilou de $72 \%$ a $84 \%$. O desempenho dos 163 alunos participantes, em termos percentuais nesse agrupamento de conhecimentos, oscilou de $75 \%$ a $81 \%$,

Neste sentido, os dados estatísticos apontaram que 0 bom desempenho nas tarefas estatísticas pelos alunos do $9^{\circ}$ ano (EF) tem relação com as crenças de autoeficácia positivas expressas em termos qualitativos de 'ser capaz' de resolver as tarefas propostas.

Em termos de força da crença, é possível afirmar que quanto mais elevadas as pontuações atribuídas na escala do tipo Likert, melhores os resultados na efetiva solução dos 5 primeiros itens das tarefas. No segundo agrupamento de conhecimento formado pelo sexto e sétimo itens, houve uma redução significativa quanto aos atributos para o nível de concordância, respectivamente, $37 \%$ e $39 \%$.

O nível de concordância para os cinco primeiros itens das tarefas da $3^{a}$ série (EM) está em uma faixa superior ao que foi apresentado para $\circ 9^{\circ}$ ano, oscilando de $79 \%$ a $93 \%$. O desempenho desses alunos nesse agrupamento de conhecimentos também superou a amostra dos alunos do 
$9^{\circ}$ ano (EF), oscilando de $78 \%$ a $85 \%$. No segundo agrupamento de conhecimento formado pelo sexto e sétimo item, assim como no $9^{\circ}$ ano (EF), teve uma redução significativa quanto aos atributos para o nível de concordância, respectivamente, $58 \%$ e $47 \%$.

As sínteses das análises abordadas no artigo de Oliveira, Pirola e Marques Junior (2020) com base no tratamento estatístico envolvendo o teste de hipótese permite-nos responder a primeira questão de investigação: existe relação entre as crenças de autoeficácia e o desempenho na resolução de tarefas estatísticas? A resposta é positiva. Uma crença positiva ou negativa tem relação direta com o desempenho dos alunos, a partir da força expressa na crença de autoeficácia.

Os participantes da amostra da $3^{a}$ série (EM) tiveram melhores rendimentos do que os alunos do $9^{\circ}$ ano (EF), pois nessa amostra há 146 alunos com pontuações maiores que o ponto mediano da escala $(24,5)$. Por outro lado, houve 113 alunos do $9^{\circ}$ ano (EF) com pontuações maiores que 0 ponto mediano da escala $(24,5)$.

Na próxima seção o foco são as produções escritas dos alunos das duas amostras cuja resolução foi classificada como errada. Em termos de crença de autoeficácia, "a desistência associada à baixa auto-eficácia ajuda a garantir o próprio fracasso que reduz a confiança e o ânimo" (PAJARES; OLAZ, 2008, p. 106). Entendemos o fracasso citado pelos autores como 'situação de fracasso escolar', o qual instiga a necessidade de intervenção do professor frente a aprendizagem do aluno.

\section{LACUNAS NO DESENVOLVIMENTO DO LETRAMENTO ESTATÍSTICO}

Nesta seção resgatamos o conteúdo dos itens das tarefas com foco nos elementos de conhecimento, segundo o modelo de Gal $(2002,2019)$. Em seguida, apresentamos uma solução recomendada com base nas respostas mais frequentes dos alunos com crença de autoeficácia positiva, transcritas com o uso de aspas. Por fim, com base no repertório de respostas erradas dos alunos com crenças de autoeficácia negativa, analisamos as lacunas que podem comprometer o desenvolvimento do letramento estatístico. Em 
relação ao conteúdo dos 7 itens do teste de desempenho escolar, organizamos seções secundárias agrupando os itens em 4 tarefas estatísticas.

\section{Análise da primeira tarefa}

O conteúdo da primeira tarefa envolveu as principais ocorrências policiais registradas no período de janeiro a maio, no município de Pilar do Sul, no ano de 2019, conforme síntese das informações contidas na Tabela 4:

TABELA 4 - Registro de ocorrências policiais. Município de Pilar do Sul janeiro a maio de 2019.

\begin{tabular}{cccccc}
\hline Ocorrências & janeiro & fevereiro & março & abril & Maio \\
\hline Homicídio & 2 & 2 & 0 & 1 & 2 \\
\hline Lesão corporal & 9 & 12 & 4 & 11 & 11 \\
\hline Estupro & 0 & 0 & 1 & 1 & 1 \\
\hline Roubo & 1 & 4 & 2 & 3 & 2 \\
\hline Furto & 2 & 24 & 19 & 15 & 16 \\
\hline
\end{tabular}

Fonte: adaptado de https://www.ssp.sp.gov.br/estatistica/pesquisa.aspx. Acesso em: 20 jan.2021.

Com base no conteúdo das informações expostas na Tabela 4, duas questões foram formuladas: a) identificar as variáveis estatísticas e a respectiva quantidade (frequência) de ocorrências policiais; b) interpretar as informações sobre a frequência de ocorrências policiais ocorridas no período de janeiro a maio de 2019.

A crença de autoeficácia positiva expressa por boa parte dos alunos tanto do $9^{\circ}$ ano EF quanto da $3^{a}$ série EM pode ser justificativa pelo registro escrito de um dos alunos: "as variáveis são estas da primeira coluna, ou seja, homicídio, lesão corporal, estupro, roubo e furto". No que diz respeito às frequências, "foi feita a soma das quantidades em cada uma das linhas, 7 casos de homicídio, 47 de lesão corporal, 3 de estupro, 12 roubos e 76 furtos" (relatos de uma aluna da $3^{a}$ série $\mathrm{EM}$ ).

Há lacunas na habilidade de letramento no protocolo escrito do aluno, pois homicídio, lesão corporal, estupro, roubo e furto são resultados da variável qualitativa nominal 'ocorrência policial'. Nenhum aluno fez menção aos resultados janeiro até maio como elementos da variável qualitativa ordinal que pode ser designada como 'mês'. Em relação à frequência, o correto é afirmar que foi anotado o número de ocorrências (frequência) 
para cada resultado observado da variável 'ocorrência policial', ou seja, 7 casos de homicídio, 47 de lesão corporal, 3 de estupro, 12 roubos e 76 furtos.

No item ' $b$ ' vale destacar a importância que muitos alunos deram para o contexto do tema, conforme um dos protocolos escritos: "na cidade acontece vários casos, principalmente, furto. E também porque eu já vi" (relato de um aluno do $9^{\circ}$ ano EF). Por outro lado, destacamos o caso de um aluno da $3^{a}$ série EM que respondeu corretamente o item ' $b$ ', mas exerceu uma postura crítica frente aos dados estatísticos apresentados na primeira tarefa: "Pilar do Sul é uma cidade pequena, por isso são poucos casos. Mas eu tenho certeza que os dados na linha de estupro está bem errada". Como não houve oportunidade do pesquisador questionar o participante sobre o conteúdo de sua resposta, devido ao anonimato, ficou apenas registrado em nosso relatório a argumentação.

O padrão de resposta considerada correta a partir da análise da produção escrita dos alunos, diz respeito aquilo que foi mais frequente nas ocorrências policiais: "o que mais ocorreu foi furto e lesão corporal" (relato de uma aluna do $9^{\circ}$ ano EF). No montante dessas respostas, tanto de alunos do $9^{\circ}$ ano $\mathrm{EF}$ quanto de $3^{a}$ série $\mathrm{EM}$, não houve relato escrito sobre as ocorrências com menores frequências. Passamos a analisar as respostas associadas à crença de autoeficácia negativa e sua força, de acordo com a sua frequência.

Houve 39 erros para o item ' $a$ ' da primeira questão para o $9^{\circ}$ ano EF. $O$ baixo nível de letramento estatístico envolveu o conhecimento estatístico, mais especificamente, o conceito de variável estatística. Acrescentamos que a análise dos dados revelou também demanda na habilidade de letramento manifestada por 30 alunos, pela dificuldade em saber ler tabela.

No que diz respeito à amostra de estudantes da $3^{a}$ série (EM) houve 29 erros cometidos. Destes, 19 estudantes não apresentaram quaisquer registro escrito com indício de resolução do item ' $a$ '. No item 'b' da primeira questão contabilizamos 35 erros decorrentes da crença de autoeficácia negativa dos alunos de $9^{\circ}$ ano (EF). Assim como no item ' $a$ ', os participantes da $3^{a}$ série (EM) que apresentaram respostas em branco para o item 'b' manifestaram 
uma crença de autoeficácia negativa forte. O elemento de conhecimento de contexto influenciou a crença de autoeficácia negativa, pois 16 estudantes pertencentes a uma mesma unidade escolar não acreditaram que as notificações sobre as ocorrências policiais aconteceram ou que estes dados não estão corretos.

\section{Análise da segunda tarefa}

O conteúdo da segunda tarefa envolveu a elaboração de um gráfico para a primeira tarefa, o qual relaciona cada resultado da variável "ocorrência policial" com o respectivo número (frequência) associado às ocorrências policiais. Os alunos (122 do $9^{\circ}$ ano (EF) e 129 da $3^{a}$ série (EM)), cuja crença de autoeficácia foi positiva e que apresentaram a solução correta, utilizaram dois tipos de gráficos. Cento e oito estudantes utilizaram linhas contínuas para cada ocorrência policial exposta no eixo vertical do gráfico e a sequência de meses de janeiro a maio no eixo horizontal.

O outro gráfico utilizado por 143 estudantes foi o de barras verticais, todas com mesma largura, dispostas no eixo horizontal. Cada conjunto de barras foi associado com um tipo de ocorrência policial. É importante destacar que na segunda tarefa a crença positiva exposta pelos alunos na capacidade de construir o gráfico de linhas, bem como de barras verticais, não foi suficiente para o sucesso de todos no resultado da atividade. Treze alunos do $9^{\circ}$ ano (EF) e nove da $3^{a}$ série (EM) utilizaram a configuração adequada do gráfico de linhas, mas cometeram erro na escala dos valores numéricos dispostos no eixo vertical. O mesmo tipo de erro foi repetido por 17 estudantes (nove alunos do $9^{\circ}$ ano EF e oito da $3^{a}$ série EM) na construção do gráfico de barras verticais,

Nessa tarefa privilegiamos os elementos de conhecimento matemático e estatístico, pelo fato de envolver o uso de escala e disposição da variável qualitativa nominal (ocorrência policial) e ordinal (meses), na construção do gráfico. No entanto, na leitura das respostas corretas dos alunos que atribuíram crenças de autoeficácia positiva, a postura crítica quanto à interpretação dos dados foi destaque para uma parcela de estudantes da 
$3^{a}$ série EM. Seis estudantes que manifestaram serem capazes de construir o gráfico; a crença positiva envolveu expressões como: "este gráfico não representa a realidade de Pilar do Sul". Nas duas amostras da pesquisa contabilizamos 290 respostas com crenças de autoeficácia positivas. Passamos a analisar as respostas associadas apenas à crença de autoeficácia negativa e sua força, ou seja, de acordo com 38 participantes.

Nesse sentido, primeiramente, dispomos a análise de 19 erros cometidos por alunos de $9^{\circ}$ ano (EF). Cinco alunos que manifestaram uma crença de autoeficácia negativa e forte (ponto 2 na escala Likert) expressa por "não gosto de fazer cálculos"; comprometeu a construção do gráfico pela necessidade de efetuar cálculos para estabelecer a escala apropriada. A situação de fracasso escolar quanto à capacidade de construção do gráfico também se mostrou presente nos protocolos escritos de 8 alunos, cujas crenças negativas foram: "não gosto de construir tabelas e gráficos", "não consegui elaborar o gráfico". Nos protocolos escritos de 6 alunos, não verificamos nenhum indício de tentativa de construção do gráfico. De acordo com Pajares; Olaz (2008), o misto de crença negativa e desistência conduziu ao evento de fracasso, ocasionando a falta de prédisposição em aprender.

Já com relação a 19 alunos da $3^{a}$ série (EM), 10 apresentaram respostas em branco, 5 estudantes escreveram que se sentem capazes de construir o gráfico, mas não fizeram por preguiça. Quatro alunos escreveram que não conseguiram elaborar o gráfico, impossibilitando de analisarmos quais lacunas sobre o conhecimento estatístico e matemático que comprometeram a resolução da tarefa.

\section{Análise da terceira tarefa}

Essa tarefa envolveu a apresentação de uma lista de filmes disponíveis nos cinemas da região metropolitana de Sorocaba na segunda quinzena de julho de 2019: "O Rei Leão", "Homem-Aranha: longe de casa", "Toy Story 4", "Turma da Mônica: laços", "Annabelle 3: de volta para casa" e "Pets: a vida secreta dos bichos 2". Foi proposto aos alunos as seguintes tarefas: 
a) junto com o professor responsável pela turma, elaborar uma tabela contendo a frequência dos estudantes que assistiram cada um dos filmes;

b) construir e interpretar o conteúdo do gráfico gerado pela tabela no item ' $a$ '.

A análise dessa tarefa levou em conta os dois itens conjuntamente estabelecendo primeiro, os apontamentos quanto à solução correta. Os alunos do $9^{\circ}$ ano (EF) e $3^{a}$ série (EM) tiveram desempenhos parecidos quanto à resolução correta no item ' $a$ ': 132 acertos para a amostra de estudantes do EF e 129 para estudantes do Ensino Médio. Vale ressaltar que a manifestação da crença de autoeficácia positiva dos alunos de $9^{\circ}$ ano (EF) foi quantitativamente maior (pontos na escala Likert) do que na $3^{a}$ série (EM), podendo ser decorrente do envolvimento das turmas de $9^{\circ}$ ano (EF) das duas escolas participantes da pesquisa com o Projeto Bullying, promovido pelas professoras da disciplina de Língua Portuguesa em parceria com outras disciplinas, especialmente, a Matemática.

Nas respostas escritas dos alunos de $9^{\circ}$ ano (EF) para 0 item ' $a$ ', a maioria justificou sua crença de autoeficácia positiva pelo fato de terem estudado como coletar e organizar dados no referido projeto, que teve como objetivo discutir, prevenir e combater a violência e a discriminação no âmbito de cada unidade escolar. A representação gráfica usual dos alunos foi composta por barras verticais, com a disposição das variáveis qualitativas nominais no eixo horizontal. No eixo vertical desse gráfico, foi inserido o número de alunos que assistiram cada um dos seis filmes citados. As crenças de autoeficácia positivas desses 132 alunos do $9^{\circ}$ ano (EF) foram justificadas pelo estudo de gráficos e tabelas em várias disciplinas, como Geografia. Dialogamos com professores dessa área em duas das escolas públicas participantes da pesquisa e constatamos que tal estudo foi decorrente do tema 'Geografia das Populações', o qual envolveu discussões sobre migração, cultura, demografia em vários países.

Vamos abordar as crenças de autoeficácia negativa manifestada por 31 estudantes do $9^{\circ}$ ano (EF). Três alunos cuja justificativa para sua crença de autoeficácia negativa e forte (ponto 2 na escala Likert), estava relacionada 
ao comportamento inadequado dos seus colegas em sala de aula, o qual prejudicava o desempenho dos alunos, registraram a tabela elaborada, porém, não construíram o respectivo gráfico. Todos os estudantes que apresentaram a crença 'não gosto de elaborar gráficos' apresentaram em seus registros escritos a construção do mesmo, embora, com erros. Seis estudantes fizeram um gráfico com barras verticais com o número de alunos que assistiram cada um dos seis filmes citados, porém, com erros na construção da escala numérica no eixo vertical.

Seis estudantes escolheram um gráfico denominado Diagrama de Pareto empilhado verticalmente. Em cada barra foi associado a frequência das duas situações complementares (assistiv/não assistiu) para cada um dos filmes. Tecnicamente é um tipo de gráfico correto para a apresentação dos dados, porém, todos cometeram erros na distribuição do número de alunos que assistiram e aqueles que não assistiram determinado filme, conforme exemplo do Gráfico 6:

O gráfico de setores foi a outra representação gráfica escolhida por 16 alunos com crença negativa fraca (ponto 3 na escala Likert), expressa por "não me sinto motivado". Vale ressaltar que a falta de instrumentos como régua e transferidor e cálculos de conversão entre a quantidade de pessoas e o ângulo de cada setor circular, comprometeu essa representação gráfica.

A ausência de conhecimentos prévios no uso de escala em gráfico, cálculo de ângulo para a construção geométrica do setor circular, além do equívoco conceitual na determinação do Diagrama de Pareto empilhado constituíram lacunas no desenvolvimento do letramento estatístico. Estes apontamentos repercutiram no desempenho desses alunos do $9^{\circ}$ ano (EF) na resolução do item ' $b$ ', acrescidos de outros, no total de 37 alunos com crença negativa para a interpretação de dados solicitados no item 'b'. Esses alunos que manifestaram crença negativa em seus protocolos, não redigiram nenhum esboço de interpretação dos dados, comprometendo a habilidade de letramento. Na justificativa das crenças, houve menção de dificuldades e de não saber expressar mediante a representação gráfica. No 
entanto, os alunos tinham a disposição dos dados registrados em tabela, construída coletivamente, em cada uma das turmas.

A habilidade de letramento fez-se presente nas justificativas das crenças de autoeficácia positiva de 126 estudantes do $9^{\circ}$ ano (EF), porém, de forma restrita. Entendemos o termo restrito pelo fato dos registros escritos revelarem, na maioria das vezes, apenas um aspecto possível de interpretação dos dados. Oitenta e cinco alunos escreveram sobre o filme mais assistido pelos alunos da sua turma. Trinta e oito alunos escreveram sobre o filme menos assistido em cada turma.

Apenas 3 alunos utilizaram o conhecimento de contexto relacionado ao fato de que a cidade de Pilar do Sul não possui cinema, e geralmente as pessoas se deslocam para Sorocaba para assistir a filmes em Shopping Center, percorrendo uma distância mínima de $53 \mathrm{~km}$. Em suas respostas, houve menção ao baixo índice de colegas que assistiram os filmes citados, como, por exemplo, nesse relato: "pelo número de alunos na sala, poucos assistiram algum destes filmes, porque a cidade não tem cinema e aí é difícil sair daqui".

Passamos a analisar a terceira tarefa, com base na amostra de 165 estudantes da $3^{a}$ série (EM), na qual contabilizamos 129 acertos para 0 item 'a' e 135 acertos, provenientes de crenças de autoeficácia positiva para o item 'b'. A representação gráfica com menor frequência foi o gráfico de pizza ou de setores, elaborada por 8 estudantes. Na construção desse gráfico, esses 8 alunos mostraram capacidade e habilidade matemática tanto nos cálculos de proporção para determinar cada setor circular, quanto na utilização dos instrumentos de desenho geométrico. No que diz respeito ao conhecimento estatístico destacamos a escolha correta da representação gráfica, a partir da sua caracterização.

Os demais alunos que acertaram $O$ item ' $a$ ', um total de 121 participantes da $3^{a}$ série (EM), optaram por construir um gráfico de barras verticais, com a associação entre o nome de cada filme e a respectiva frequência de alunos. Porém, em 94 protocolos, encontramos uma coluna vertical destinada à relação "nenhum filme X quantidade de alunos". 
No item 'b', o conteúdo das respostas dos alunos que exibiram crenças positivas, no total de 135 respostas da $3^{a}$ série (EM), não foram divergentes em relação aos alunos de $9^{\circ}$ ano EF. Porém, como a maioria dos alunos relacionou em sua representação gráfica (item 'a') uma coluna para aqueles colegas de turma que não assistiram nenhum dos filmes citados, no item 'b', 61 respostas escritas apresentaram postura crítica sobre o contexto do tema. Mais especificamente, apenas em uma turma de $3^{a}$ série $E M$, houve um número maior de alunos que assistiram pelo menos um dos 6 filmes listados. Nesse sentido, a questão financeira ganhou destaque nos registros escritos analisados.

As crenças negativas de estudantes da $3^{a}$ série EM para o item ' $a$ ' da terceira tarefa, entre elas, a expressão "dificuldade na construção de gráfico" não constituiu um obstáculo para a realização da atividade, embora com erros. Por exemplo, 4 alunos de uma mesma turma de $3^{a}$ série (EM) recorreram ao gráfico de setores, no entanto, houve alunos que assistiram mais de um filme e, consequentemente, a soma dos ângulos centrais dos setores circulares ultrapassou $100 \%$ da região circular.

\section{Análise da tarefa 4}

No item ' $a$ ' que envolveu calcular a moda e mediana do preço por litro do etanol e da gasolina, houve 115 respostas do $9^{\circ}$ ano (EF) catalogadas como erradas e 106 na $3^{a}$ série (EM). A repercussão dessa situação resultou em protocolos totalmente em brancos ou, as vezes, com algum valor monetário aparentemente expressando uma possível resposta. No entanto, nenhum procedimento aritmético para fundamentar aquele possível valor registrado.

No que diz respeito às respostas corretas e crenças positivas exibidas por 107 participantes ao todo, a maioria, teve nível forte: 36 alunos do $9^{\circ}$ ano (EF) e 42 estudantes da $3^{a}$ série (EM). Os demais estudantes (29 ao todo) de ambas as amostras demonstraram uma crença positiva muito forte. Em termos de justificativa para a crença de autoeficácia, muitos alunos de dessas amostras recorreram aos aspectos conceituais. Para a 'moda' 
tivemos 53 respostas associadas à expressão que mais aparece e 42 optaram pelo valor mais frequente. Os demais estudantes, 12 ao todo, relacionaram o cálculo do valor modal com expressões: "lembro da matéria, é fácil".

A ausência da base conceitual estatística sobre medidas de tendência central, especialmente, no que se refere à mediana e moda, comprometeu a possibilidade de realização dos procedimentos matemáticos necessários para obter os referidos valores.

O item ' $b$ ' propõe a análise sob a perspectiva econômica quanto à afirmação: "só vale a pena abastecer o veículo com etanol se o preço do litro deste combustível for menor que $70 \%$ do preço do litro da gasolina".

A quantidade de respostas consideradas erradas no item 'b' foi 119 para alunos do $9^{\circ}$ ano (EF) e 104 erros para a $3^{a}$ série (EM). Desse montante de alunos, 13 alunos que expressaram dificuldades em lidar com números e com porcentagem apresentaram registros escritos ausentes dos procedimentos operatórios próprios para a solução da tarefa. A situação de fracasso escolar no desempenho dessa tarefa foi decorrente da falta de habilidade de letramento indicada na expressão de 31 estudantes ao manifestarem "dificuldades de compreender as informações". A justificativa "dificuldade em lidar com números e com porcentagem" expressa por 60 estudantes constitui-se uma lacuna de conhecimento matemático.

Vinte e um alunos de $9^{\circ}$ ano (EF) justificaram a ausência de resolução da referida tarefa "por não ter aprendido a matéria ou não ter estudado isto". Releva-se nesse argumento uma contradição quanto à prescrição do Currículo do estado de São Paulo no estudo de medidas de tendência central nos anos finais do Ensino Fundamental (SÃO PAULO, 2012).

A crença de autoeficácia negativa de 76 alunos de que afirmaram "não sabiam fazer" ou "não tinham interesse na tarefa" corrobora com Pajares e Olaz (2008): o misto de crença negativa forte e muito forte conduziu ao evento de fracasso escolar. Os demais estudantes não apresentaram a resolução do item 'b'. 
Em relação aos 105 estudantes que tiveram êxito na resolução do item 'b', duas abordagens foram descritas em seus protocolos escritos. A maioria, 73 estudantes, calcularam $70 \%$ do preço da gasolina com base no posto de combustível com valor mais alto e mais baixo, deste combustível. Concluíram que para esses valores extremos do preço da gasolina, o valor do etanol foi superior aquele anunciado nessa tarefa. Logo, é viável abastecer com etanol por conta de um custo mais baixo em quaisquer de um dos 12 postos de combustível.

A minoria, 32 estudantes, calcularam $70 \%$ do preço médio da gasolina em cada um dos 12 postos de combustivel e na comparação com os respectivos valores de etanol, concluíram que em termos econômicos, é mais vantajoso abastecer com etanol.

As análises que apresentamos com base nos protocolos escritos dos estudantes permite-nos responder a segunda questão de investigação: que lacunas os alunos apresentam no decorrer das suas atividades estatísticas que comprometem o desenvolvimento do letramento estatístico?

Nas duas amostras com estudantes de $9^{\circ}$ ano (EF) e $3^{a}$ série (EM) foram reveladas lacunas quanto ao conhecimento matemático, mais especificamente, o uso de escalas em gráficos, cálculo de porcentagem, proporção, mediana e moda, além de habilidades na construção de gráfico de setores. No que diz respeito às habilidades de letramento, a lacuna ocorreu na interpretação de dados em gráficos ou tabelas, bem como a compreensão do conteúdo de cada tarefa.

O contexto envolvendo as tarefas com o tema cinema, ocorrências policiais e variabilidade no preço de combustível potencializou a postura crítica de diversos alunos. No entanto, constituiu uma lacuna para o letramento estatístico, em situações de ausência de resolução para os itens envolvidos das tarefas, por desinteresse sobre o tema ou crença negativa sobre a veracidade dos dados, mesmo diante da exposição da referência utilizada na formulação da questão proposta. 


\section{CONSIDERAÇÕES FINAIS}

No geral, a amostra fornada por 165 estudantes da $3^{a}$ série (EM) apresentou um desempenho melhor do que 163 participantes do $9^{\circ}$ ano (EF). Temos como pressuposto que estudos de conteúdos da disciplina Geografia envolvendo populações e o projeto sobre o tema Bullying, constituíram episódios escolares que contribuíram no desempenho dos alunos de $9^{\circ}$ ano (EF). Particularmente, isso diz respeito aos cinco primeiros itens das tarefas que contemplaram a coleta, organização, representação e interpretação de dados, por meio da construção de tabelas e gráficos.

No que diz respeito aos dois últimos itens que envolveram o cálculo da mediana, razão ou proporção, além da interpretação dos seus resultados, temos como pressuposto que a abordagem escolar desses conceitos estatísticos pode influenciar de forma positiva no desempenho do teste escolar aplicado. Porém, no período de aplicação das 4 tarefas estatísticas, os participantes, provavelmente estudaram o conteúdo de medidas de tendência central nas aulas de Matemática, pelo menos no $6^{\circ}$ ano (EF), tomando por base o Currículo do estado de São Paulo (SÃO PAULO, 2012).

Levantamos a hipótese que o espaço de tempo entre a aprendizagem formal desse conteúdo programático e o momento escolar da aplicação do teste de desempenho escolar pode ter gerado uma situação de fracasso escolar referente aos itens da quarta tarefa. Nesse sentido, interpretamos a ausência da base conceitual sobre medidas de tendência central como uma das lacunas no nível do letramento estatístico.

Para o cumprimento dos propósitos dessa pesquisa, consideramos o percurso metodológico desde a sua natureza, escolha e aplicação do instrumento de coleta de dados e a forma de análise das informações obtidas, adequados para responder as questões de investigação. No entanto, no decorrer da leitura dos protocolos escritos dos alunos, encontramos possibilidades de continuidade de pesquisas nessa temática. A diversidade de temas que podem suscitar discussões estatísticas são amplas e, de acordo com as turmas que desenvolvemos tais abordagens, podemos questionar que contextos relevantes e desenvolver projetos para 0 
letramento estatístico.

Os procedimentos metodológicos utilizados nessa pesquisa não contemplaram a intervenção pedagógica do professor. No entanto, a inclusão de entrevistas ou vídeo gravação de interlocuções em sala de aula, podem constituir-se instrumentos de coleta de dados potenciais na análise do letramento estatístico, em relação à postura crítica dos alunos quanto à interpretação das informações estatísticas.

$\mathrm{Na}$ seção "Escala de autoeficácia acadêmica" respondemos a primeira questão norteadora da pesquisa, explicitando argumentos que mostraram a relação entre a crença de autoeficácia e o desempenho dos estudantes.

Em relação à segunda questão de investigação (que lacunas os alunos apresentam no decorrer das suas atividades estatísticas que comprometem o desenvolvimento do letramento estatístico?), no geral, a amostra fornada por 165 estudantes da $3^{a}$ série (EM) apresentou um desempenho escolar melhor do que 163 participantes do $9^{\circ}$ ano (EF).

Vale salientar que estudos de conteúdos da disciplina Geografia envolvendo populações e o projeto sobre o tema Bullying, constituíram episódios escolares que contribuíram de forma positiva no desempenho escolar dos alunos de $9^{\circ}$ ano (EF). Particularmente, isso diz respeito aos cinco primeiros itens das tarefas que contemplaram a coleta, organização, representação e interpretação de dados, por meio da construção de tabelas e gráficos.

No que diz respeito aos dois últimos itens que envolveram o cálculo da mediana, razão ou proporção, além da interpretação dos seus resultados, temos como pressuposto que a abordagem escolar desses conceitos estatísticos podem influenciar nos resultados da aplicação do instrumento de coleta de dados. No período de aplicação das quatro tarefas estatísticas, os sujeitos participantes da pesquisa, provavelmente estudaram o conteúdo de medidas de tendência central nas aulas de Matemática, pelo menos no $6^{\circ}$ ano do EF, tomando por base o Currículo do Estado de São Paulo (SÃO PAULO, 2012). 
Levantamos a hipótese que o espaço de tempo entre a aprendizagem formal desse conteúdo programático e o momento escolar da aplicação do instrumento de coleta de dados pode ter gerado uma situação de fracasso escolar referente aos itens da quarta tarefa. Nesse sentido, interpretamos a ausência da base conceitual sobre medidas de tendência central como uma das lacunas para o desenvolvimento do letramento estatístico; foco da segunda questão de investigação.

Os resultados da análise dos protocolos escritos dos estudantes das duas amostras (alunos de $9^{\circ}$ ano (EF) e da $3^{a}$ série (EM)), revelaram lacunas quanto ao conhecimento matemático, mais especificamente, o uso de escalas em gráficos, cálculo de porcentagem, proporção, mediana e moda, além de habilidades na construção de gráfico de setores.

No que diz respeito às habilidades de letramento, a lacuna ocorreu na interpretação de dados em gráficos ou tabelas, bem como a compreensão do conteúdo de cada tarefa.

O contexto envolvendo as tarefas com o tema cinema, ocorrências policiais e variabilidade no preço de combustível potencializou a postura crítica de diversos alunos. No entanto, constituiu uma lacuna para 0 letramento estatístico, em situações de ausência de resolução para os itens envolvidos das tarefas, por desinteresse sobre o tema ou crença negativa sobre a veracidade dos dados, mesmo diante da exposição da referência utilizada na formulação da tarefa proposta.

\section{REFERÊNCIAS}

BANDURA, A. Self-efficacy. In: RAMACHAUDRAN, V. S. (ed.). Encyclopedia of human behavior. New York: Academic Press, 1994, vol. 4, p. 71-81.

BANDURA, A.; AZZI, R. G.; POLYDORO, S. A. J. (orgs.). Teoria Social Cognitiva: conceitos básicos. São Paulo: Artmed, 2008.

BRITO, M. R. F. Um estudo sobre as atitudes em relação à Matemática em estudantes de $1^{\circ}$ e $2^{\circ}$ graus. 1996. 383f. Tese (Livre docência) - Universidade Estadual de Campinas, Faculdade de Educação, Campinas, SP, 1996.

BUSSAB, W.O.; MORETTIN, P.A. Estatística Básica. 9a ed. São Paulo: Saraiva, 2017. 
COBELLO, L.S.; OLIVEIRA, P.C. Um produto educacional para o letramento estatístico no Ensino Médio. Caminhos da Educação Matemática em Revista, Sergipe, v. 9, n. 2, p. 187-204, 2019.

CRESWELL, J. W. Projeto de pesquisa: métodos qualitativo, quantitativo e misto. Tradução: Magda Lopes. $3^{a}$ ed. Porto Alegre: Artmed, 2010.

GAL, I. Adults' statistical literacy : meanings, components, responsibilites.

International Statistical Review, v. 70, n. 1, p. 1-50, 2002.

GAL, I. Understanding statistical literacy: About knowledge of contexts and models. In: CONTRERAS, J. M. et al. (ed.). Congreso Internacional Virtual de Educación Estadística, 3., 2019, Granada. Actas... Granada: Universidade de Granada, 2019. 15 p. Disponível en:

http://www.ugr.es/local/fam126/civeest.html. Acesso em: 29 jan. 2021.

MARTINS, M. E.G.; PONTE, J.P. Organização e tratamento de dados. Portugal: Ministério da Educação, 2010.

OLIVEIRA, P.C.; MACEDO, P.C. Gráfico de setores: implicações dos registros de representação semiótica para o letramento estatístico. Educação Matemática em

Revista, São Paulo, v. 23, p. 118-131, 2018.

OLIVEIRA, P.C.;PIROLA, N.A.; MARQUES JUNIOR, E. Validação da escala de crença de autoeficácia de estudantes em relação ao letramento estatístico.

Educação Matemática em Revista- RS, Porto Alegre, v.2, n.21, p.137-149, 2020.

PAJARES, F.; OLAZ, F. Teoria social cognitiva e autoeficácia: Uma visão geral. In: BANDURA, A.; AZZI, R. G.; POLYDORO, S. A. J. (Eds.). Teoria cognitiva: conceitos básicos. Porto Alegre: Artmed, 2008, pp. 97-114.

SANDER, G. P.; PIROLA, N. A.; BROCARDO, J. Crença de autoeficácia na resolução de tarefas numéricas de alunos do ciclo de alfabetização. UTSUMI, M.C. (org.). Pesquisas em psicologia da educação matemática: avanços e atualidades. São Carlos: Pedro \& João Editores, 2020, pp.77-103.

SÃO PAULO. Secretaria da Educação. Currículo do Estado de São Paulo: Matemática e suas tecnologias - Ensino Fundamental (Ciclo II) e Ensino Médio. Coordenação de área: MACHADO, N.J.. $1^{a}$ ed. atual. São Paulo: SEE, 2012. 72p.

VIEIRA, S. Introdução à Bioestatística. $4^{a}$ ed. Rio de Janeiro: 2011 . 345p.

Submissão em: 29 de janeiro de 2021.

Aprovado em: 04 de agosto de 2021.

Publicado em: 11 de agosto de 2021. 